\title{
OPTIMIZATION OF MICROALGAE OIL EXTRACTION UNDER ULTRASOUND AND MICROWAVE IRRADIATION
}

José Miguel Bermúdez Menéndez ${ }^{\mathrm{a}}$, Ana Arenillas ${ }^{\mathrm{a}}$, Jose Ángel Menéndez Díaz ${ }^{\mathrm{a}}$, Luisa Boffa $^{\mathrm{b}}$, Stefano Mantegna ${ }^{\mathrm{b}}$, Giancarlo Cravotto ${ }^{\mathrm{b} *}$

${ }^{a}$ Instituto Nacional del Carbón, CSIC, Aparatado 73, 33080 Oviedo, Spain, Tel. +34985119090, Fax. +34985297662

${ }^{b}$ Dipartimento di Scienza e Tecnologia del Farmaco, Università degli Studi di Torino, via P. Giuria 9, 10125, Torino, Italy. $\quad$ *giancarlo.cravotto@unito.it

\begin{abstract}
Background. Microalgae are one of the most promising biofuel sources that the world has to offer, although the conversion process is hampered by technical and economic problems mainly related to de-watering and extraction. The efficiency of the process can be dramatically improved by means of non-conventional techniques such as ultrasound (US) and microwaves (MW). However, their energy efficiency must also be taken into account.

Results. In the present work different solvents (chloroform/methanol mixtures, hexane, acetone and pure methanol) and procedures (Bligh-Dyer and Folch as conventional, MW and US as non-conventional) were tested to find the best conditions for lipid extraction from Nannochloropsis gaditana microalga. The energy consumption of USand MW-assisted microalgae oil extraction processes have been compared with classical procedures.
\end{abstract}


Conclusion. Chloroform/methanol mixtures (for Bligh-Dyer and Folch) and methanol (for non-conventional techniques) gave comparable fatty acids (FA) w/w \% on dried microalgae. The highest extraction yield and lowest energy consumption was found to occur under MW irradiation, especially at high temperatures under pressure.

\section{Keywords}

Microalgae; Extraction; Microwave; Ultrasound; Biofuels

\section{Introduction}

One of the main scientific tasks of the third millennium is the cost-effective exploitation of renewable energy sources in pursuit of minimal environmental impact. ${ }^{1}$ Many alternatives have been proposed and, in the case of the transportation industry, biofuels seem to be the most promising. They are already in use in some countries and further expansion is expected..$^{2-4}$ Several technological, economic and social barriers have yet to be overcome in conventional biofuel production. The fact that it competes for use of arable land with food production has also started an ethical debate in emerging economies because of high water and fertiliser requirements and the issue of biodiversity conservation. ${ }^{5}$ For these reasons, classical biofuel crops have been gradually replaced by microalgae that can produce up to 10 times more oil per cultivated area than traditional oil plants. ${ }^{1,6-11}$ There are other benefits to be gained from the use of aquatic as opposed to terrestrial biomass; (i) relatively fast growth allows harvesting to be carried out on a daily basis, (ii) microalgae use light more efficiently, (iii) their growth is unaffected by weather conditions, (iv) they have lower water consumption needs than oilseed crops, (v) there is no need for the use of herbicides and pesticides in their 
cultivation, (vi) they can be grown in brackish water on non-arable land and use waste water a as source of nutrients (specially nitrogen), (vii) microalgae biomass production can affect the biofixation of waste $\mathrm{CO}_{2}(1 \mathrm{~kg}$ of dry algal biomass utilises about $1.83 \mathrm{~kg}$ of $\mathrm{CO}_{2}$ ), (viii) a larger number of species are available and their genetic manipulation in order to modify their chemical composition (e.g. lipid content) is relatively easy, (ix) besides biofuels, several valuable co-products (such as omega-3, carotenoids and poly unsaturated fatty acids "PUFA") with different applications (human nutrition, animal feed and aquaculture, biofertilization, as a source of PUFA and proteins) can be obtained in the process. ${ }^{4,} 8,10-17$ All these advantages explain why microalgae are regarded as "biotechnology's green gold". ${ }^{18}$ Despite these advantages, several reviews have been recently trying to answer the questions about the true commercial viability of large scale production of biodiesel from microalgae, analyzing all the steps of the process from the energy balance point of view. ${ }^{19,20}$

Currently the drying and extraction processes represent the most critical steps in terms of energy consumption. ${ }^{6-8,10,11,18,19}$

Conventional extraction techniques are usually time-consuming and may cause degradation or unwanted chemical changes in the products. Working at higher temperatures can lower treatment times but leads to processes with high energy demands. Of the novel extraction techniques that are gaining interest, US- and MWassisted processes are playing the leading role. Microalgae extraction accomplishes two of the "Six Principles of Green Extraction"21 per se (innovation by selection of varieties and use of renewable plant resources, and secondly, the production of co-products instead of waste that can include the bio- and agro-refining industry). The use of US- or MW-assisted extraction covers two additional principles (reducing energy consumption 
by energy recovery and the use of innovative technologies, and secondly, reducing unit operations and favouring safe, robust and controlled processes) making this an even greener process.

Several works have studied the efficiency of the extraction techniques, from the extraction yield point of view, and have concluded that the US and MW based processes are the most efficient techniques. ${ }^{4,6-8,22,23}$

Recent papers have proposed different lipid extraction methods on microalgae, showing an improvement with MW or US-assisted protocols. ${ }^{14,24,25}$ However, no work so far has dealt with their efficiency from an energy viewpoint. The aim of the present fill this gap by focusing on the yields and energetic consumption of the US- and MW-assisted extraction of bio-oils from the microalgae Nannochloropsis gaditana, using the most suitable solvent mixture.

\section{Experimental}

$\underline{\text { Raw Material }}$

The microalgae selected for the extraction study was Nannochloropsis gaditana supplied by Exeleria, S.L. (fatty acids percentage in cell dry weight near $13 \%$, CleanAlgae). The algal biomass was dried in the harvesting facilities and then supplied to the lab for the experiments.

\section{Equipment}

Extraction under high-intensity US was performed using probe systems developed in our laboratories in collaboration with Danacamerini (Torino, Italy). The working power setting was $100 \mathrm{~W}$. Two high-power devices were used: an immersion horn (19.5 kHz), and a cavitating tube, which is a cup horn-like system consisting of a thin hollow 
titanium cylinder fixed to a booster $(21 \mathrm{kHz}) .^{22}$ The extraction temperature was kept between 50 and $60^{\circ} \mathrm{C}$ by means of a thermostated cooling system (Fig. 1).

MW-assisted extractions were carried out in a professional multimode oven operating at 2.45 GHz (Microsynth-Milestone, BG Italy), in a closed Teflon vessel. The extraction temperature was kept constant at $60 / 90^{\circ} \mathrm{C}$ and monitored by an optical fibre thermometer. The MW device modulated the power used with the aim of keeping the operating temperature constant. The power varied in the range of $25-30 \mathrm{~W}$ for the extractions carried out at $60^{\circ} \mathrm{C}$ and in the range of $30-35 \mathrm{~W}$ for the extraction performed at $90^{\circ} \mathrm{C}$.

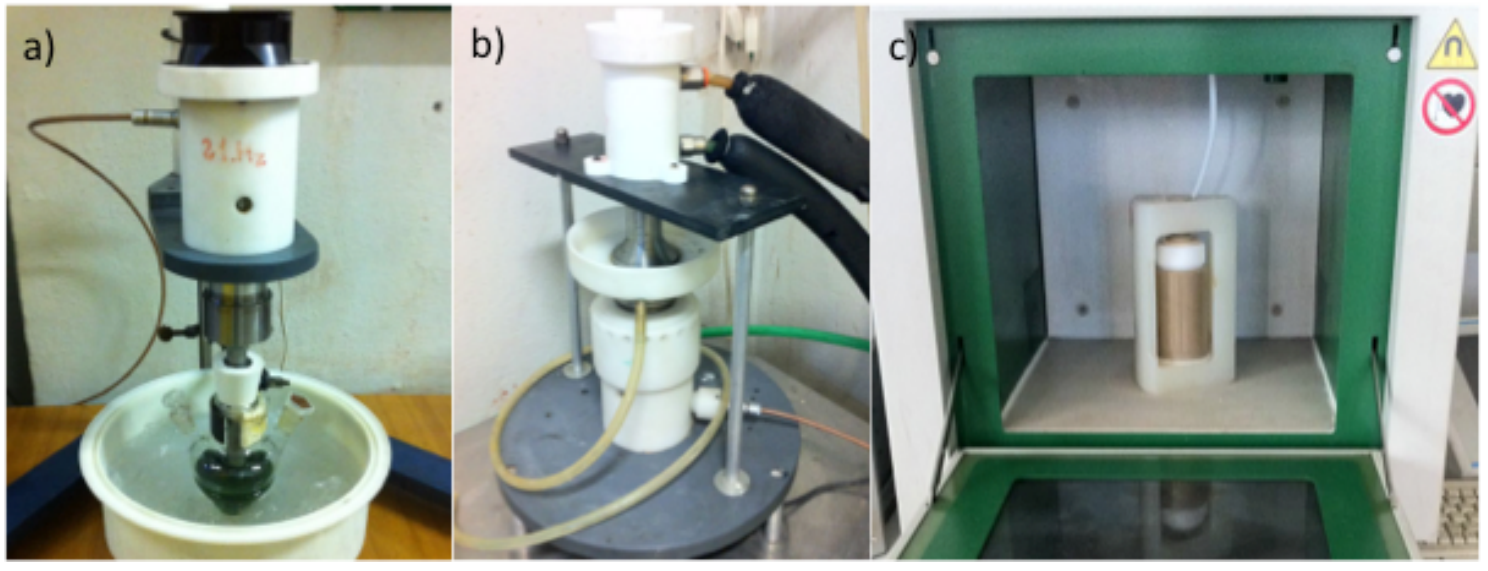

Figure 1. a) US horn, b) US cavitation tube, c) MW oven.

\section{$\underline{\text { Lipid extraction }}$}

A weighed amount of dried microalgae $(5 \mathrm{~g})$ was suspended in the solvent $(50 \mathrm{~mL}$, ratio of 1:10 g/mL, or $250 \mathrm{ml}$, ratio of 1:50 g/ml). The different techniques were applied in a time range of 5 - 60 minutes and at temperatures from room temperature (rt) up to $90^{\circ} \mathrm{C}$. Different solvents were tested; a $\mathrm{H}_{2} \mathrm{O} / \mathrm{CHCl}_{3} / \mathrm{MeOH}$ 1:1:2 mixture (Bligh and Dyer), ${ }^{26}$ a $\mathrm{CHCl}_{3} / \mathrm{MeOH}$ 2:1 mixture (Folch) ${ }^{27}$ hexane, acetone and $\mathrm{MeOH}$. Once the extraction 
was completed, the mixture was filtered by means of a sintered glass Buchner funnel and the solvent was evaporated. In the case of the $\mathrm{H}_{2} \mathrm{O} / \mathrm{CHCl}_{3} / \mathrm{MeOH} 1: 1: 2$ mixture, $\mathrm{H}_{2} \mathrm{O}$ and $\mathrm{CHCl}_{3}$ (1:1) were added to form a biphasic system after filtration. In the case of $\mathrm{CHCl}_{3} / \mathrm{MeOH}$ 2:1 mixture, $\mathrm{H}_{2} \mathrm{O}$ was added to form a biphasic system after filtration with a final ratio $\mathrm{CHCl}_{3} / \mathrm{MeOH} / \mathrm{H}_{2} \mathrm{O}$ 8:4:3. The organic phase containing the lipidic fraction was separated and evaporated under vacuum. When necessary, the aqueous layer was extracted with $\mathrm{CHCl}_{3}(1-2 \times 20-50 \mathrm{ml})$.

\section{Fatty acid (FA) characterization}

Several derivatization methods were tested to select the most efficient protocol of transesterification of the triglycerides and other ester derivatives (i.e. carotenoids FA esters) and esterification of any free FA present in our vegetal matrix.

The method A was proposed by Ríos et al. in $2013 .{ }^{25}$ A weighed amount of extract (ca. $30 \mathrm{mg}$ ) and an internal standard (FA C23, ca. $0.4 \mathrm{mg}$ ) were suspended in a $\mathrm{MeOH} / \mathrm{HCl} / \mathrm{CHCl}_{3}(4.5 \mathrm{~mL})$ mixture and heated at $80^{\circ} \mathrm{C}$ under magnetic stirring for $4 \mathrm{~h}$. After cooling, $\mathrm{H}_{2} \mathrm{O}(1.5 \mathrm{ml})$ was added and the sample well mixed. Finally, a 4:1 $\mathrm{Hex} / \mathrm{H}_{2} \mathrm{O}$ mixture $\left(3 \times \mathrm{x}^{4} \mathrm{ml}\right)$ was added to the mixture for the extraction of lipidic fraction. The organic layers were collected, dried on anhydrous $\mathrm{Na}_{2} \mathrm{SO}_{4}$ and filtered before GC analysis.

In the method $\mathrm{B},{ }^{28}$ a weighed amount of extract (ca. $30 \mathrm{mg}$ ) and an internal standard (FA C23, ca. $0.4 \mathrm{mg}$ ) were suspended in a $\mathrm{MeOH} / \mathrm{H}_{2} \mathrm{SO}_{4}$ mixture $(5 \mathrm{~mL}$ ) and heated at $80^{\circ} \mathrm{C}$ under magnetic stirring for $4 \mathrm{~h}$. After cooling, $\mathrm{H}_{2} \mathrm{O}(10 \mathrm{ml})$ was added and the sample well mixed. Finally, hexane $(2 \times 3 \mathrm{ml})$ was added to the mixture for the 
extraction of lipidic fraction. The organic layers were collected, dried on anhydrous $\mathrm{Na}_{2} \mathrm{SO}_{4}$ and filtered before GC analysis.

In the method $\mathrm{C}$, the extract was treated according to the protocol first proposed by Lepage and $\mathrm{Roy}^{29}$ and later modified by Xu et al. ${ }^{30}$ A weighed amount of extract (ca. $30 \mathrm{mg}$ ) and an internal standard (FA C23, ca. $0.4 \mathrm{mg}$ ) were suspended in a $0.5 \mathrm{~N} \mathrm{NaOH}$ solution in $\mathrm{MeOH}(3 \mathrm{~mL})$ and heated at $75^{\circ} \mathrm{C}$ under magnetic stirring for $10 \mathrm{~min}$. After cooling, a $1 \mathrm{~N}$ solution of acetyl chloride in $\mathrm{MeOH}(1 \mathrm{~mL})$ was added to the mixture and kept at $75^{\circ} \mathrm{C}$ under magnetic stirring for $10 \mathrm{~min}$. Finally, $\mathrm{H}_{2} \mathrm{O}(3 \mathrm{ml})$ and hexane $(2$ x $2 \mathrm{ml}$ ) were added to the mixture. The heterogeneous sample was vigorously shaken. After the phase separation, the upper layers (hexane) were collected, dried on anhydrous $\mathrm{Na}_{2} \mathrm{SO}_{4}$ and filtered before $\mathrm{GC}$ analysis.

After some analyses on two different extracts, the method A was chosen for all the samples, giving the best result in FA recovery (for details, see Supporting Information). The GC-MS qualitative analyses were performed in an Agilent Technologies 6850 Network GC System with a 5973 Network Mass Selective Detector and 7683B Automatic Sampler, using a capillary column (HP-5MS 5\% Phenyl Methyl Siloxane, length $30 \mathrm{~m}$; i.d. $0.25 \mathrm{~mm}$; film thickness $0.25 \mu \mathrm{m})$.

The GC-MS quantitative analyses were performed in an Agilent Technologies 7820A Network GC System equipped with a FID detector, using a capillary column (Mega WAX, length $30 \mathrm{~m}$; i.d. $0.25 \mathrm{~mm}$; film thickness $0.25 \mu \mathrm{m}$ ) on the basis of the internal standard amount.

FAME identification was performed checking the correspondence with C8-C24 saturated and unsaturated external standards (Sigma-Aldrich), prepared the solutions 
with a GC grade cyclohexane, and with Wiley275 and NIST05 GC libraries (only for GC-MS analyses).

Additional experimental information is provided in the supplementary material.

\section{Energy calculation}

The way to determine the energy consumption of each technique was different depending on the equipment. In the case of the US devices, it was set a working power, which multiplied by the extraction time gives the total energy consumption. In the case of the MW device, as it was said, the power provided by the device is modulated with the aim of keeping the operating temperature. For this reason, it is not possible to multiply the power by the extraction time, since power is not constant. However, the software of the device has the possibility of integrate the curve power vs. time in order to obtain the energy consumed.

\section{Results and discussion}

$\underline{\text { Solvent selection }}$

The first step in the procedure of this research work was to select the best solvent or solvent mixture and plant/solvent ratio. The experiments were performed at room temperature for $1 \mathrm{~h}$ under magnetic stirring (conventional extraction). Table 1 shows the yields achieved in each experiment. The results are expressed as follows:

$$
\text { Extraction yield }(\%)=\frac{\text { mass of extract }}{\text { mass of dried microalgae }} \cdot 100
$$




$$
\begin{gathered}
F A / E x(\%)=\frac{\text { mass of extracted } F A}{\text { mass of extract }} \cdot 100 \\
F A / D M(\%)=\frac{\text { mass of extracted } F A}{\text { mass of dried microalgae }} \cdot 100
\end{gathered}
$$

Table 1. Yields obtained by means of different solvents and plant/solvent ratio, at $\mathrm{rt}$ for

\begin{tabular}{|c|c|c|c|c|}
\hline Sample & $\begin{array}{c}\text { Plant/solvent } \\
\text { ratio }\end{array}$ & $\begin{array}{l}\text { Extraction } \\
\text { Yield (\%) }\end{array}$ & $\begin{array}{l}\text { FA/Ex } \\
\text { (\% av.) }\end{array}$ & $\begin{array}{c}\text { FA/DM } \\
\text { (\% av.) }\end{array}$ \\
\hline Bligh Dyer & $1: 10$ & 8.9 & 81.24 & 6.74 \\
\hline Bligh Dyer & $1: 50$ & 15.5 & 78.47 & 12.18 \\
\hline Folch & $1: 10$ & 12.3 & 85.90 & 10.56 \\
\hline Folch & $1: 50$ & 28.1 & 54.76 & 15.40 \\
\hline Hexane & $1: 10$ & 0.73 & - & - \\
\hline Acetone & $1: 10$ & 1.1 & - & - \\
\hline $\mathrm{MeOH}$ & $1: 10$ & 33.0 & 32.00 & 9.71 \\
\hline
\end{tabular}
$1 \mathrm{~h}$ (derivatization method A)

$\mathrm{CHCl}_{3} / \mathrm{MeOH}$ mixtures enable both polar and non-polar lipids to be extracted, unlike hexane. In literature, two different methods are proposed for lipid extraction, namely Bligh and Dyer (BD) and Folch (FO). These protocols were tested at different plant/solvent ratio to identify the best conditions for a reference extraction (Table 1). The BD protocol with a 1:10 plant/solvent ratio gave the lowest extraction yield (8.9\%), showing however a high selectivity in lipids extraction $(81.24 \%)$ with a FA/DM w/w 
av. $\%$ of 6.74 . This percentage could be increased to $12.18 \%$ with a $1: 50$ plant/solvent ratio. The FO procedure gave in general a higher extraction yield related also to a higher FA/DM w/w av. $\%$. Using a 1:50 ratio, the extraction yield was $28.1 \%$, with a $15.40 \%$ of free FA in dried microalgae.

The weight of these extract can be considered a gravimetric measurement of the lipid content of the vegetal matrix. ${ }^{31}$

Different solvents were tested for lipid extraction from microalgae using the lowest plant/solvent ratio $(1: 10)$ in order to find an alternative to $\mathrm{CHCl}_{3} / \mathrm{MeOH}$ mixtures. The extractions carried out with hexane and acetone were not satisfactory and gave only $0.73 \%$ and $1.11 \%$ yields respectively. As reported in Table 1, the best solvent was $\mathrm{MeOH}$ which gave a $33.00 \%$ extraction yield and a comparable value of $\mathrm{FA} / \mathrm{DM}$ w/w $\%$ to FO protocol (1:10), 9.71 vs $10.56 \%$.

The $\mathrm{CHCl}_{3} / \mathrm{MeOH}$ mixtures were more selective than $\mathrm{MeOH}$ in the extraction of lipids containing FA.

Our purpose was to propose a green protocol to maximize the FA yield for biofuel production, using the lowest solvent amount, avoiding the use of toxic chlorinated solvents with the lowest energy consumption.

Therefore we performed the extractions in $\mathrm{MeOH}(1: 10)$ using different nonconventional techniques, such as US and MW, to promote extraction yields and obtain the highest FA/DM w/w \%.

\section{Extraction yields}

The influence of temperature on the extraction was confirmed by the conventional heating yields: around $33 \%$ at $\mathrm{rt}$ for $1 \mathrm{~h}$ and $38.3 \%$ at $60^{\circ} \mathrm{C}$ for $45 \mathrm{~min}$, respectively 
(Table 1 and 2). All the extractions therefore were carried out at $60^{\circ} \mathrm{C}(\mathrm{MeOH}$ boiling point $65^{\circ} \mathrm{C}$ ), with the exception of the $\mathrm{MW}$-assisted extraction which was also performed at $90^{\circ} \mathrm{C}$, as it is able to work under high pressure (MW u.p.).

Table 2. Extraction yields obtained by different techniques.

\begin{tabular}{|c|c|c|c|c|c|}
\hline Technique & $\begin{array}{l}\text { Temp. } \\
\left({ }^{\circ} \mathrm{C}\right)\end{array}$ & $\begin{array}{l}\text { Time } \\
\text { (min) }\end{array}$ & $\begin{array}{l}\text { Extraction } \\
\text { yield (\%) }\end{array}$ & $\begin{array}{c}\mathbf{F A} / \mathbf{E x}^{\mathrm{a}} \\
(\%)\end{array}$ & $\begin{array}{c}\text { FA/DM } \\
(\%)\end{array}$ \\
\hline Conventional & 60 & 15 & 31.3 & 33.04 & $10.33 \pm 0.29$ \\
\hline Conventional & 60 & 30 & 36.2 & 33.90 & $12.27 \pm 0.35$ \\
\hline Conventional & 60 & 45 & 38.3 & 35.50 & $13.59 \pm 0.39$ \\
\hline US horn & $50-60$ & 5 & 31.4 & 38.28 & $12.00 \pm 0.34$ \\
\hline US horn & $50-60$ & 10 & 33.0 & 37.97 & $12.52 \pm 0.36$ \\
\hline US horn & $50-60$ & 15 & 35.8 & 36.09 & $12.92 \pm 0.37$ \\
\hline US horn & $50-60$ & 20 & 36.2 & 38.91 & $14.11 \pm 0.40$ \\
\hline US cav. tube & $50-60$ & 5 & 31.5 & 35.66 & $11.21 \pm 0.32$ \\
\hline US cav. tube & $50-60$ & 10 & 32.6 & 37.89 & $12.34 \pm 0.36$ \\
\hline US cav. tube & $50-60$ & 15 & 36.9 & 36.04 & $13.29 \pm 0.38$ \\
\hline US cav. tube & $50-60$ & 20 & 38.1 & 38.72 & $14.76 \pm 0.42$ \\
\hline MW & 60 & 10 & 29.7 & 41.53 & $12.33 \pm 0.36$ \\
\hline MW & 60 & 20 & 39.6 & 36.24 & $14.36 \pm 0.41$ \\
\hline MW (u.p.) & 90 & 10 & 40.0 & 37.06 & $14.82 \pm 0.43$ \\
\hline
\end{tabular}


A relation between the extraction yield and extraction time was established for each technique in order to identify the shortest time needed to obtain the best result. The results are summarized in Table 2 and outlined in Graph 1.

As can be seen, conventional extraction was the least effective technique, as it gave a $36.2 \%$ extraction yield and a $12.27 \% \mathrm{FA} / \mathrm{DM} \%$ in $30 \mathrm{~min}$ at $60^{\circ} \mathrm{C}$. When the time was extended to $45 \mathrm{~min}$, an extraction yield of $38.2 \%$ and a FA/DM $\%$ of $13.59 \%$, were obtained, the best result achieved with this technique.

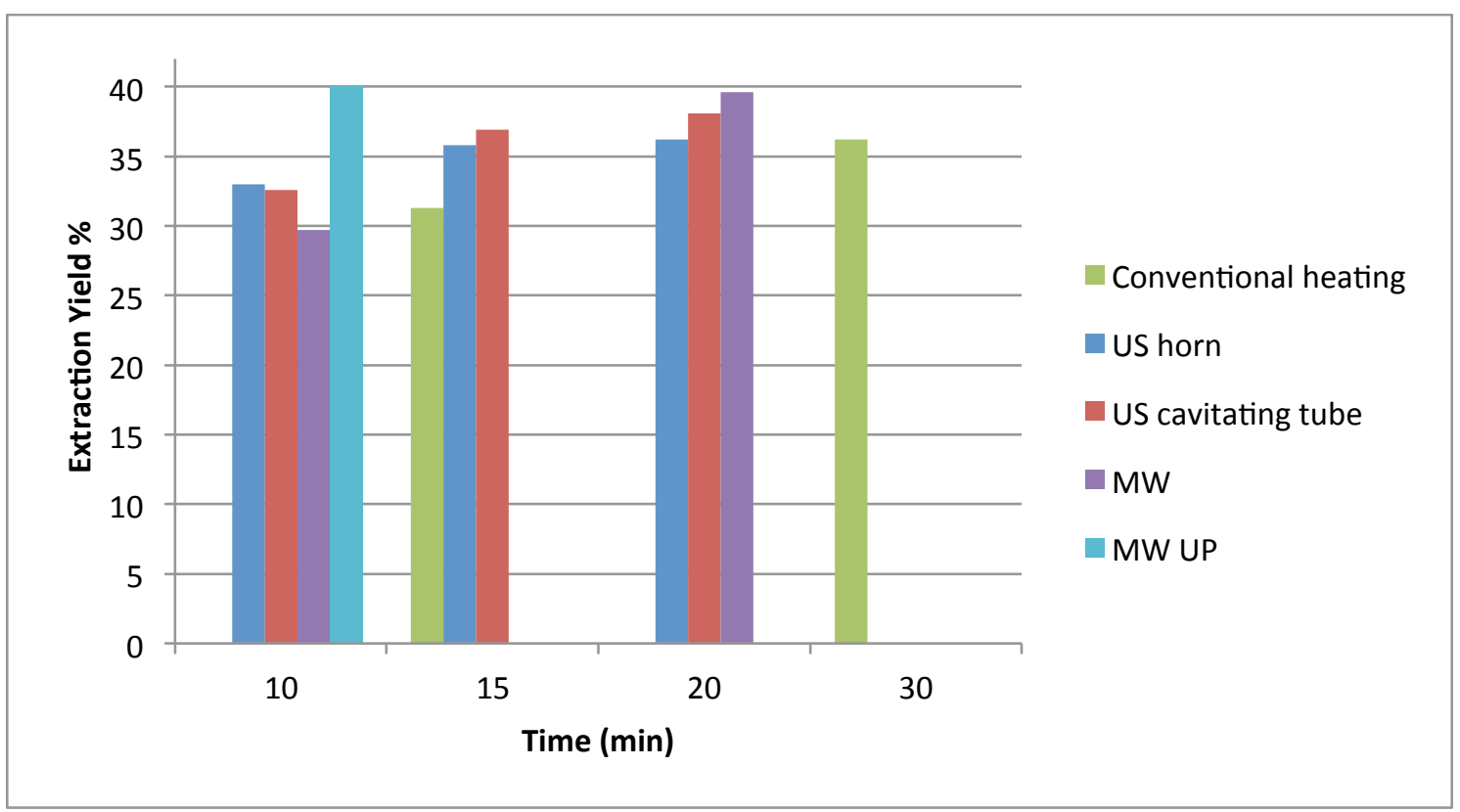

Graphic 1. Extraction yield (\%) of Nannochloropsis gaditana in the presence of $\mathrm{MeOH}$ (1:10 ratio) using different techniques at different times.

The US extraction carried out in the cavitating tube provided the same extraction yield in $20 \mathrm{~min}$ as the conventional technique in $45 \mathrm{~min}$ (around $38.1 \%$ ), whereas the US horn was not able to equal this value $(36.2 \%$ yield) in the same time (see Graphic 1$)$. However, from the FA/DM \% value, it can be seen that both the US extraction in the 
cavitating tube and with the US horn gave an higher FA yield in 20 min, than the conventional extraction in $45 \mathrm{~min}$ (see Table 2 and Graphic 2), 14.76\% and $14.11 \%$ respectively.

Both techniques were superior to conventional extraction, but the protocol that uses the cavitating tube was preferred because it afforded a better control of the process. The results obtained using MW assisted extraction were especially interesting. When the extraction temperature was set at $60^{\circ} \mathrm{C}$, it was possible to obtain a very high extraction yield in $20 \mathrm{~min}(39.6 \%)$ and a FA/DM \% that was slightly higher than that achieved with conventional extraction in $45 \mathrm{~min}$ and US horn in $20 \mathrm{~min}$. Extraction carried out in 10 min, gave significantly lower yields, but the best selectivity for FA (41.53\%). However, when the extraction temperature was increased to $90^{\circ} \mathrm{C}$ and the process was carried out under pressure, the best results were achieved in only $10 \mathrm{~min}$ (see Table 2 and Graphic 2). In fact, a FA/DM percentage of $14.82 \%$ was obtained, comparable with those obtained with FO extraction (1:50 plant/solvent ratio).

As in the case of US extraction techniques, it was concluded that MW extraction was more efficient than conventional extraction. When US and MW extractions are compared, it is difficult to conclude which technology provided the best results, even though MW extraction was slightly more efficient than US extraction. 


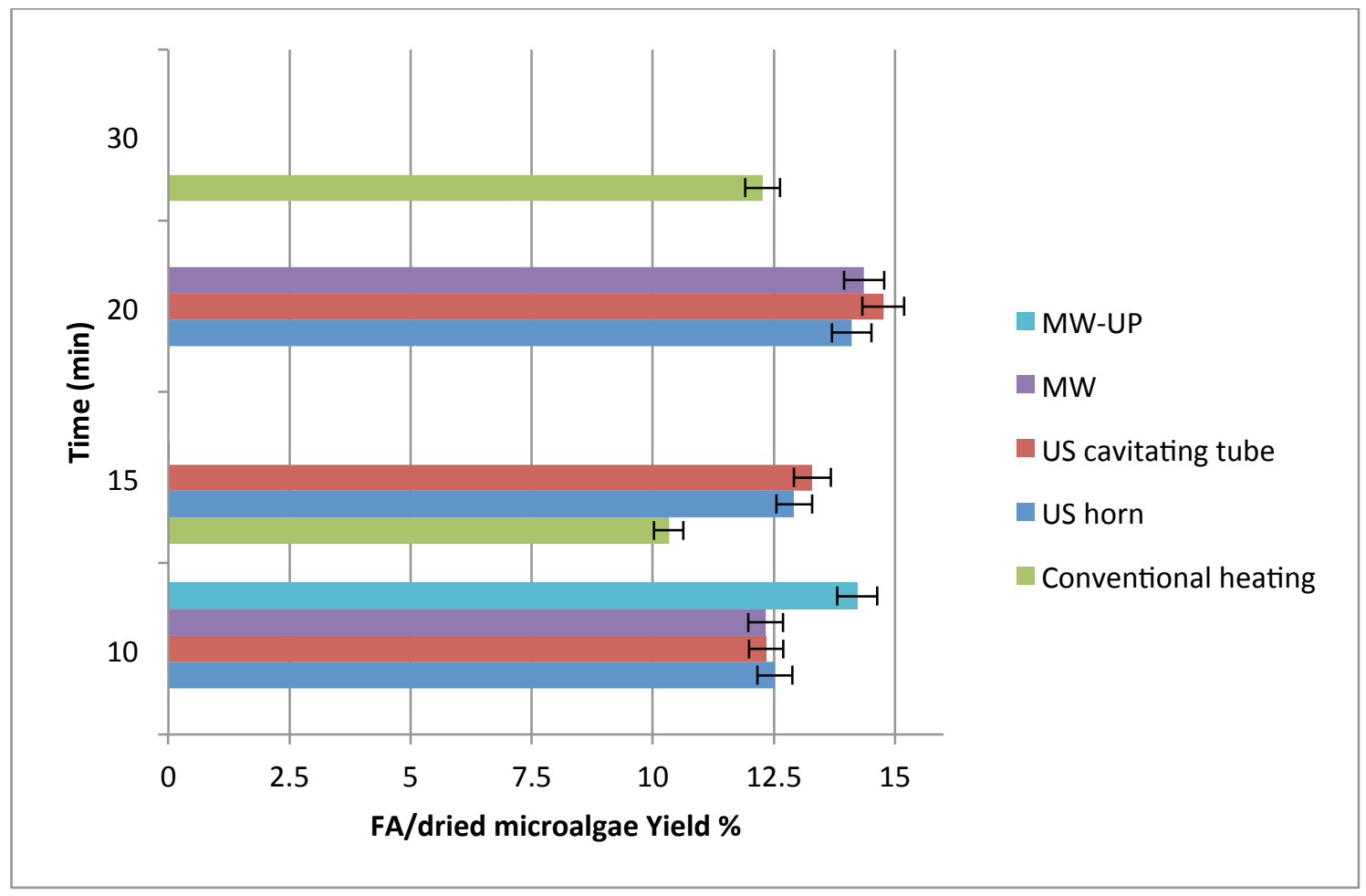

Graphic 2. Free FA \% (w/w) in dried microalgae from GC-MS analyses of methanolic extracts (1:10 ratio) subjected to derivatization. A comparison of different techniques and times.

With respect to FA characterization, Table 3 shows the results of characterization of the extracts obtained under the conditions that gave the best result for each technique, compared to $\mathrm{BD}$ and FO extractions. The FA composition of the extracts obtained under US irradiation (cav. tube, $20 \mathrm{~min}, 50-60^{\circ} \mathrm{C}, 1: 10$ plant/MeOH ratio) and $\mathrm{MW}$ u.p. (10 min, $90^{\circ} \mathrm{C}, 1: 10$ plant $/ \mathrm{MeOH}$ ratio) show no significant differences with the results of the characterization obtained with the conventional FO protocol $(60 \mathrm{~min}, \mathrm{rt}, 1: 50$ plant/solvent- $\mathrm{CHCl}_{3} / \mathrm{MeOH}$ 2:1 mixture- ratio). 
Table 3. FA w/w percentage in dried microalgae: comparison of the best result with each technique.

\begin{tabular}{|c|c|c|c|c|c|c|c|}
\hline FA & $\begin{array}{c}\text { BD 1:50 } \\
1 \mathrm{~h}, \mathrm{rt}\end{array}$ & $\begin{array}{c}\text { FO 1:50 } \\
1 \mathrm{~h}, \mathrm{rt}\end{array}$ & $\begin{array}{c}\text { Conv. 1:10 } \\
45 \mathrm{~min}, 60^{\circ} \mathrm{C}\end{array}$ & $\begin{array}{c}\text { US horn 1:10 } \\
20 \mathrm{~min}, 50-60^{\circ} \mathrm{C}\end{array}$ & $\begin{array}{l}\text { US cav. tube } 1: 10 \\
20 \mathrm{~min}, 50-60^{\circ} \mathrm{C}\end{array}$ & $\begin{array}{c}\text { MW 1:10 } \\
20 \mathrm{~min}, 6^{\circ} \mathrm{C}\end{array}$ & $\begin{array}{c}\text { MW (u.p.) 1:10 } \\
10 \mathrm{~min}, 90^{\circ} \mathrm{C}\end{array}$ \\
\hline $\mathrm{C} 14$ & 0.416 & 0.560 & 0.673 & 0.575 & 0.615 & 0.583 & 0.595 \\
\hline $\mathrm{C} 16$ & 3.104 & 3.680 & 3.628 & 3.567 & 3.691 & 3.598 & 3.651 \\
\hline C16:1 (n9) & 1.934 & 2.440 & 2.226 & 2.274 & 2.342 & 2.351 & 2.327 \\
\hline C16:2 (n6) & 0.711 & 0.926 & 0.863 & 0.872 & 0.943 & 0.884 & 0.935 \\
\hline C16:3 (n3) & 0.908 & 1.172 & 1.038 & 1.142 & 1.174 & 1.136 & 1.175 \\
\hline C18:1 (n9) & 0.517 & 0.637 & 0.526 & 0.613 & 0.638 & 0.627 & 0.622 \\
\hline C18:2 (n6) & 1.730 & 2.309 & 1.833 & 2.049 & 2.196 & 2.093 & 2.258 \\
\hline $\mathrm{C} 18: 3$ (n3) & 1.438 & 1.947 & 1.530 & 1.712 & 1.773 & 1.742 & 1.801 \\
\hline C20:4 (n6) & 0.259 & 0.335 & 0.252 & 0.265 & 0.286 & 0.286 & 0.278 \\
\hline C20:5 (n3) & 1.047 & 1.392 & 1.020 & 1.045 & 1.098 & 1.055 & 1.176 \\
\hline
\end{tabular}


Energy consumption

Table 4 shows the energy consumption data expressed as energy consumed per gram of total extract $\left(\mathrm{W} \cdot \mathrm{h} / \mathrm{g}_{\text {Ex }}\right)$, per gram of FA extracted $\left(\mathrm{W} \cdot \mathrm{h} / \mathrm{g}_{\mathrm{FA}}\right)$ and per gram of dried, treated microalgae $\left(\mathrm{W} \cdot \mathrm{h} / \mathrm{g}_{\mathrm{DM}}\right)$.

Table 4. Energy consumption for the non-conventional techniques.

\begin{tabular}{lccccc}
\hline Technique & Temperature & Time & \multicolumn{3}{c}{ Consume } \\
\cline { 5 - 6 } & $\left({ }^{\circ} \mathbf{C}\right)$ & $(\mathbf{m i n})$ & $\mathbf{W} \cdot \mathbf{h} / \mathbf{g}_{\mathbf{E x}}$ & $\mathbf{W} \cdot \mathbf{h} / \mathbf{g}_{\mathbf{F A}}$ & $\mathbf{W} \cdot \mathbf{h} / \mathbf{g}_{\text {DM }}$ \\
\hline US horn & $50-60$ & 5 & 5.3 & 13.9 & 1.7 \\
US horn & $50-60$ & 10 & 10.1 & 26.6 & 3.3 \\
US horn & $50-60$ & 15 & 14.0 & 38.7 & 5.0 \\
US horn & $50-60$ & 20 & 18.4 & 47.2 & 6.7 \\
US cav. tube & $50-60$ & 5 & 5.3 & 14.9 & 1.7 \\
US cav. tube & $50-60$ & 10 & 10.2 & 27.0 & 3.3 \\
US cav. tube & $50-60$ & 15 & 13.6 & 37.6 & 5.0 \\
US cav. tube & $50-60$ & 20 & 17.5 & 45.2 & 6.7 \\
MW & 60 & 10 & 2.9 & 6.9 & 0.9 \\
MW & 60 & 20 & 4.3 & 11.8 & 1.7 \\
MW (u.p.) & 90 & 10 & 4.1 & 10.9 & 1.6 \\
\hline
\end{tabular}

As can be seen MW extraction consumes less energy than US extraction. Only in the case of the shortest extraction times $(5 \mathrm{~min})$ can US techniques be considered competitive against MW extraction. However, energy consumption is still higher and the yields are quite lower, which will lead to higher cultivation and harvesting costs. 
MW extraction would appear to be the best technique from the energy point of view. The lowest energy consumption was obtained when the extraction was carried out at $60^{\circ} \mathrm{C}$ and $10 \mathrm{~min}$, but the extraction yields were slightly higher at $60^{\circ} \mathrm{C}$ in $20 \mathrm{~min}$ and at $90^{\circ} \mathrm{C}$ in $10 \mathrm{~min}$. In the light of these findings it is clear that the selection of the best operating conditions needs to be addressed using a wider approach that includes the whole production process, from the cultivation of the microalgae to the final product. To show how far this technology has progressed, and to underline the need for further development, the energy consumption of these techniques may be compared with the theoretical maximum energy that can be obtained from microalgae. In the report called National Algal Biofuels Technology Roadmap, ${ }^{9}$ the U.S. Department of Energy has established that a maximum amount of energy of approximately $5 \mathrm{Wh} / \mathrm{g}$ can be obtained. If this is the case, only MW assisted extraction can currently be used for the extraction of bio-oils from microalgae to produce biofuels. However, it seems that it will be necessary to keep working to improve these values to make the process more feasible as there are other energy intense processes which give rise to high energy consumption and the total energy requirement of the process would probably be higher than the $5 \mathrm{Wh} / \mathrm{g}$ value.

\section{Conclusions}

The extraction of bio-oils from microalgae using US- and MW-assisted extraction has been studied. This work further highlights the advantages of US and MW reactors for extracting bio-oils from microalgae.

Of the different solvents and protocols tested, only $\mathrm{CHCl}_{3} / \mathrm{MeOH}$ mixtures (for $\mathrm{BD}$ and FO) and $\mathrm{MeOH}$ (non-conventional techniques) gave comparable $\mathrm{FA} / \mathrm{DM} \mathrm{w} / \mathrm{w} \%$. 
Although the $\mathrm{CHCl}_{3} / \mathrm{MeOH}$ mixtures gave rise to the best FA extraction selectivity, $\mathrm{MeOH}$ combined to MW or US irradiation can be considered the best solvent for this process for different reasons, among them the lower amount of solvent required, the absence of chlorinated in waste (reduced environmental impact), the lower extraction time.

Moreover, it gives the possibility to perform directly the transesterification step on the extract obtained, or, as proposed in few cases in literature, ${ }^{32}$ to perform extraction and transesterification simultaneously.

In terms of energy consumption, MW assisted extraction showed the best results as it was able to perform the extraction using considerably lower amounts of energy than the US assisted extraction technique. These results show that, currently, MW extraction is the best technique for extracting bio-oils from microalgae and, what is one more important, it is potentially scalable for producing biofuel from microalgae.

\section{Acknowledgements}

JMB acknowledges the support received from the CSIC JAE Program. Financial support from the CDTI and Exeleria S.L. (Project CENIT VIDA) is also acknowledged. GC acknowledges the Regione Piemonte and the Interreg-ALCOTRA 2007-2013 (project: eco-extraction transfrontaliere).

\section{References}

1. Demirbas A and Demirbas MF, Importance of algae oil as a source of biodiesel. Energy Conversion and Management 52:163-170 (2011).

2. C. o. t. E. Communities, Brussels (2007). 
3. C. o. t. E. Communities, Brussels (2008).

4. Patil PD, Reddy H, Muppaneni T, Mannarswamy A, Schuab T, Holguin FO, Lammers P, Nirmalakhandan N, Cooke P and Deng S, Power dissipation in microwave-enhanced in situ transesterification of algal biomass to biodiesel. Green Chemistry 14:809-818 (2012).

5. I. E. Agency, Energy Technology Essentials: Biodiesel Production (2007).

6. Brennan L and Owende P, Biofuels from microalgae - A review of technologies for production, processing, and extractions of biofuels and co-products. Renewable \& Sustainable Energy Reviews 14:557-577 (2010).

7. Cooney M, Young $\mathrm{G}$ and Nagle N, Extraction of Bio-oils from Microalgae. Separation and Purification Reviews 38:291-325 (2009).

8. Samorì C, Torri C, Samorì G, Fabbri D, Galletti P, Guerrini F, Pistocchi R and Tagliavini E, Extraction of hydrocarbons from microalga Botryococcus braunii with switchable solvents. Bioresource Technology 101:3274-3279 (2010).

9. U.S. DOE National Algal Biofuels Technology Roadmap, ed. by Fishman D, Majumdar R, Morello J, Pate R and Yang J. U.S. Department of Energy, Office of Energy Efficiency and Renewable Energy, Biomass Program, College Park, Maryland, pp 1-124 (2010). http://biomass.energy.gov (for more information).

10. Chisti Y, Biodiesel from microalgae. Biotechnology Advances 25:294-306 (2007).

11. Sharma YC, Singh B and Korstad J, A critical review on recent methods used for economically viable and eco-friendly development of microalgae as a potential feedstock for synthesis of biodiesel. Green Chemistry 13:2993-3006 (2011).

12. Chisti Y, Biodiesel from microalgae beats bioethanol. Trends in Biotechnology 26:126-131 (2008). 
13. An JY, Sim SJ, Lee JS and Kim BW, Hydrocarbon production from secondarily treated piggery wastewater by the green alga Botryococcus braunii. Journal of Applied Phycology 15:185-191 (2003).

14. Koberg M, Cohen M, Ben-Amotz A and Gedanken A, Bio-diesel production directly from the microalgae biomass of Nannochloropsis by microwave and ultrasound radiation. Bioresource Technology, 2011, 102, 4265-4269.

15. Shen Y, Yuan W, Pei Z and Mao E, Culture of Microalga Botryococcus in Livestock Wastewater. Transactions of the ASABE 51:1395-1400 (2008).

16. Rosenberg JN, Oyler GA, Wilkinson L and Betenbaugh MJ, A green light for engineered algae: redirecting metabolism to fuel a biotechnology revolution. Current Opinion in Biotechnology 19:430-436 (2008).

17. Moreno R, Aita GM, Madsen L, Gutierrez DL, Yao SM, Hurlburt B and Brashear S, Identification of naturally isolated Southern Louisiana's algal strains and the effect of higher $\mathrm{CO}_{2}$ content on fatty acid profiles for biodiesel production. Journal of Chemical Technology and Biotechnology 88:948-957 (2013).

18. Waltz E, Biotech's green gold? Nature Biotechnology 27:15-18 (2009).

19. Rawat I, Kumar RR, Mutanda T and Bux F, Biodiesel from microalgae: A critical evaluation from laboratory to large scale production. Applied Energy 103:444-467 (2013).

20. Lam MK and Lee KT, Microalgae biofuels: A critical review of issues, problems and the way forward. Biotechnology Advances 30:673-690 (2012).

21. Chemat F, Vian MA and Cravotto G, Green Extraction of Natural Products: Concept and Principles. International Journal of Molecular Sciences 13:8615-8627 (2012). 
22. Cravotto G, Boffa L, Mantegna S, Perego P, Avogadro M and Cintas P, Improved extraction of vegetable oils under high-intensity ultrasound and/or microwaves. Ultrasonics Sonochemistry 15:898-902 (2008).

23. Lee JY, Yoo C, Jun SY, Ahn CY and Oh HM, Comparison of several methods for effective lipid extraction from microalgae. Bioresource Technology 101:S75-S77 (2010).

24. Pereira Neto AM, Sotana de Souza RA, Leon-Nino AD , D'arc Aparecida da Costa J, Sbrolini Tiburcio R, Abreu Nunes T, Sellare de Mello TC, Takashi Kanemoto F, Prado Saldanha-Corrêa FM and Flores Gianesella SM, Improvement in microalgae lipid extraction using a sonication-assisted method. Renewable Energy 55:525-531 (2013).

25. Ríos SD, Castañeda J, Torras C, Farriol X and Salvadó J, Lipid extraction methods from microalgal biomass harvested by two different paths: screening studies toward biodiesel production. Bioresour Technol. 133:378-388 (2013).

26. Bligh EG and Dyer WJ, A rapid method of total lipid extraction and purification. Canadian journal of biochemistry and physiology 37:911-917 (1959).

27. Folch J, Lees M and Sloane Stanley GH. A simple method for the isolation and purification of total lipides from animal tissues. J Biol Chem 226:497-509 (1957).

28. Converti A, Casazza AA, Ortiz EY, Perego P, Del Borghi M, Effect of temperature and nitrogen concentration on the growth and lipid content of Nannochloropsis oculata and Chlorella vulgaris for biodiesel production. Chemical Engineering and Processing: Process Intensification 48:1146-1151 (2009). 
29. Lepage G and Roy CC, Improved recovery of fatty acid through direct transesterification without prior extraction or purification. Journal of Lipid Research 25:1391-1396 (1984).

30. Xu N, Zhang X, Fan X, Han L and Zeng C, Effects of nitrogen source and concentration on growth rate and fatty acid composition of Ellipsoidion sp. (Eustigmatophyta). Journal of Applied Phycology 13:463-469 (2001).

31. Shadidi F, Extraction and Measurement of Total Lipids, in Current Protocols in Food and Analytical Chemistry, ed by Wrolstad RE, Acree TE, Decker EA, Penner MH, Reid DS, Schwartz SJ, Shoemaker CF, Smith DM and Sporns P. Wiley, unit D.1.1.1-D.1.1.11 (2001).

32. Carvalho RM, Vargas JVC, Ramos LP, Marino CEB, Torres JCL, Microalgae biodiesel via in situ methanolysis. Journal of Chemical Technology and Biotechnology 86:1418-1427 (2011). 